\title{
Review Article \\ Prevalence of Rhinitis in Athletes: Systematic Review
}

\author{
Pavol Surda, ${ }^{1}$ Abigail Walker, ${ }^{1}$ Matus Putala, ${ }^{2}$ and Pavel Siarnik ${ }^{3}$ \\ ${ }^{1}$ Department of Otorhinolaryngology, Guy's and St Thomas' University Hospital, London, UK \\ ${ }^{2}$ Department of Physical Education and Sports, Comenius University, Bratislava, Slovakia \\ ${ }^{3}$ Department of Neurology, Faculty of Medicine, Comenius University, Bratislava, Slovakia
}

Correspondence should be addressed to Pavol Surda; pavol.surda@gmail.com

Received 8 March 2017; Accepted 9 July 2017; Published 9 August 2017

Academic Editor: Peter S. Roland

Copyright (C) 2017 Pavol Surda et al. This is an open access article distributed under the Creative Commons Attribution License, which permits unrestricted use, distribution, and reproduction in any medium, provided the original work is properly cited.

\begin{abstract}
Background. Prevalence of rhinitis in athletes has frequently been studied and varies widely from $27 \%$ to $74 \%$. The aim of this systematic review was to examine the prevalence of rhinitis in athletes, to specifically compare the evidence of rhinitis in landbased and aquatic athletes. Methods. Systematic search of MEDLINE, EMBASE, and the non-MEDLINE subset of PubMed was performed from inception to March 8, 2016, to identify studies on rhinitis in athletes. Results. Of the 373 identified unique articles, a total of 13 studies satisfied the criteria for this review. The final group contained 9 cohort and 4 case-control studies. We found 10 studies that reported the prevalence of allergic rhinitis (21\%-56.5\%). In contrast, nonallergic rhinitis was identified by only 1 author (6\%). We have also evaluated the prevalence of rhinitis in the separate subgroups (land, water, and cold air) where swimmers seem to be the most affected (40\%-74\%), followed by cross-country skiers (46\%) and track and field athletes (21 to 49\%). Conclusion. We did not reveal any convincing trend of a higher prevalence in land-based athletes compared to general population. By contrast, aquatic and cold air athletes demonstrate increased prevalence reflecting the irritant effects of their environment on the nasal mucosa.
\end{abstract}

\section{Introduction}

Peak sporting performance requires optimal levels of health and fitness. Rhinitis, with its proven detrimental effects on sleep and mood [1], and its association with asthma [2], has clear potential for compromising athletic ability.

The acute effects of exercise on the nose have been well delineated-vasoconstriction of the capacitance vessels results in a measurable increase in nasal volume [3]. In aerobic exercise, nasal minute ventilation increases absolutely but proportionately contributes less than at rest, as the low resistance oral airway is used preferentially [4]. The impact on nasal physiology of repeated exercise training is less well established. Many of the environments and endeavours in which athletes are immersed have the potential for harm to the nasal mucosa. For example, an exercise which takes place in cold air (skiers, snowboarders, and ice hockey) or in chlorinated water (swimmers, divers, and water polo) subjects the nasal mucosa to local irritants. Aerobic exercise which takes place outdoors may result in inhalation of above average volumes of aeroallergens, nitrous oxide, or pollution due to the increased minute ventilation required to sustain activity $[5,6]$.
Rhinitis in athletes has frequently been studied in combination with asthma, and although there are many literature estimates of prevalence in the athletic population, the estimates of frequency of rhinitis vary widely-from $27 \%$ to $74 \%[7,8]$ - which may in part be attributable to differences in the studied populations (e.g., swimmers and runners), the aetiology of the rhinitis studied (irritative, allergic, or undefined), or the diagnostic criteria used.

The reported prevalence of $\mathrm{AR}$ in normal population differs from country to country. In a study using the ARIA definition on the European population, the prevalence was found to be around $25 \%$ and ranged from $17 \%$ to $28.5 \%$ [9]. Moreover, an increasing trend in prevalence of AR has been observed over the last decades of the past millennium but in the last 25 years this trend seems to be tailed off $[10,11]$. The prevalence of NAR in the normal population is not as well studied as AR but NAR has been reported to account for from 17 to $52 \%$ of all cases of rhinitis in adults $[12,13]$.

The aim of this systematic review was to examine the prevalence of rhinitis in athletes, to specifically compare the evidence of rhinitis in land-based and aquatic athletes. 


\section{Methods}

We sought to investigate the prevalence of rhinitis in athletes. The inclusion criteria were as follows: study must evaluate only human study subjects who reached age of 12 years, contain abstract, and be published in the English language between January 1980 and October 2015. We defined an athlete as a person who trains more than 6 hours/week. We classified sports into three categories which represent their different environments: land, water, and cold air.

Our review followed the PRISMA (Preferred Reporting Items for Systematic Reviews and Meta-Analysis) guidelines for reporting. P.S. and A.W. performed a systematic search of MEDLINE (OVID), EMBASE (OVID), and the nonMEDLINE subset of PubMed from inception to March 8, 2016, to identify studies on rhinitis in athletes. Both controlled vocabulary (including MeSH-terms) and words in title, abstract, and author keywords were searched. We excluded studies indexed with animals, but not indexed with humans, conference abstracts and case reports, and studies with trauma or concussion in the title. The search consisted of two concepts: athletes (including all kinds of athletic sports, swimming, and high intensity training) and rhinitis (consisting of synonyms for rhinitis and symptoms and underlying mechanisms of and tests for rhinitis). We cross-checked the reference lists and the citing articles of the identified relevant papers and adapted the search in case of additional relevant studies. The bibliographic records retrieved were imported and deduplicated using ENDNOTE.

Studies meeting the inclusion criteria were assessed on quality using the PRISMA/AMSTAR checklist as a guideline. The studies which did not discuss the subject were excluded. No minimum was set on the number of study subjects.

2.1. Data Collection. All abstracts and full-text articles were reviewed by two researchers (P.S. and A.W.) using the following inclusion criteria: cohort designs (case report, case series, other noncohort study designs, and nonsystematic reviews were excluded).

Information obtained from each article included authors, year of publication, number of participants, number of participants per category (land/water/cold air), study design, outcomes, and prevalence. Findings were tabulated and descriptively analysed, listing outcomes measured.

According to the ARIA document, allergic rhinitis is clinically defined as a symptomatic disorder of the nose, induced after allergen exposure due to an immunoglobulin IgEmediated inflammation. Symptoms of allergic rhinitis include rhinorrhea, nasal obstruction, nasal itching, and sneezing which are reversible spontaneously or with treatment [25]. Based on duration of symptoms, ARIA subdivides AR into intermittent or persistent. NAR is defined as symptoms of rhinitis without positive skin prick test [26].

In this review, we studied the overall prevalence of rhinitis regardless of the phenotype and also AR and NAR separately. The methods used for diagnosis of rhinitis are markedly heterogeneous and in surveys studying athletes poorly reported. Therefore, we reviewed the literature to find the most suitable definition for rhinitis in athletes.
We included the studies with the diagnosis of rhinitis (both nonallergic (NAR) and allergic rhinitis (AR)) based on the "self-reported physician diagnosis/physician diagnosis" or positive answers in a questionnaire. In the case of AR, this had to be accompanied with at least one positive skin prick test result/positive serum specific IgE-test.

\section{Results}

A systematic review of titles, abstracts, and full-text publications was performed as described in Figure 1. Of the 373 identified unique articles, a total of 13 studies satisfied the criteria for this review. The characteristics are illustrated in Table 1. Demographic details and efforts to control confounding were incompletely reported. Nine cohort and 4 case-control studies were included. Five authors used for diagnosis the questionnaire with or without SPT/positive serum specific IgE-test and 8 self-reported physician diagnosis/physician diagnosis. A quantitative meta-analysis was not performed due to the heterogeneity of the outcome data.

We found 10 studies that reported the prevalence of AR in which the prevalence ranged from $21 \%$ to $56.5 \%$. In contrast, NAR was identified by only 1 author (prevalence 6\%) [7].

We have also evaluated the prevalence in the separate subgroups (land, water, and cold air). Rhinitis in swimmers was studied by 3 authors who reported prevalences ranging from $40 \%$ to $74 \%[8,21,22]$. Rong et al. reported prevalence of physician-diagnosed AR in 56.5\% [21]. Two authors focused on the prevalence of overall rhinitis (AR + NAR) which was reported as $40 \%$ and $74 \%[8,22]$. We identified only one study which distinguished the specific prevalence for athletes training in cold environment, reporting rhinitis in 46\% [15]. Using track and field athletes to represent the land subgroup does not reveal an increased incidence of AR when compared with the general population (21 to $49 \%$ ) [7, 17].

\section{Discussion}

This systematic review of the literature demonstrates that the analysis of the prevalence of rhinitis in athletes is hindered by a relatively wide range of reported results and heterogeneity of methods used for diagnosis which are in surveys studying athletes poorly reported.

Lack of consensus evidence and critical reviews on this topic led us to perform this systematic review to examine the prevalence of rhinitis in athletes. Unfortunately, a quantitative meta-analysis was not possible to perform due to the heterogeneity of the outcome data.

As illustrated in Table 1, athletes as a whole population do not seem to suffer with AR more often than general population. The prevalence of AR ranged widely between $21 \%$ and $56.5 \%$. NAR, although evaluated by only 1 author, was found to be $6 \%$ (Table 1 ). The true prevalence of NAR in normal population is not known, and precise data are difficult to obtain as NAR can coexist with allergic rhinitis, and therefore the comparison between athletes and normal population is difficult to perform $[12,27]$. Noticeable is also the stable prevalence of $\mathrm{AR}$ in athletes over the last 25 years which is comparable with the normal population [10, 11]. It is 


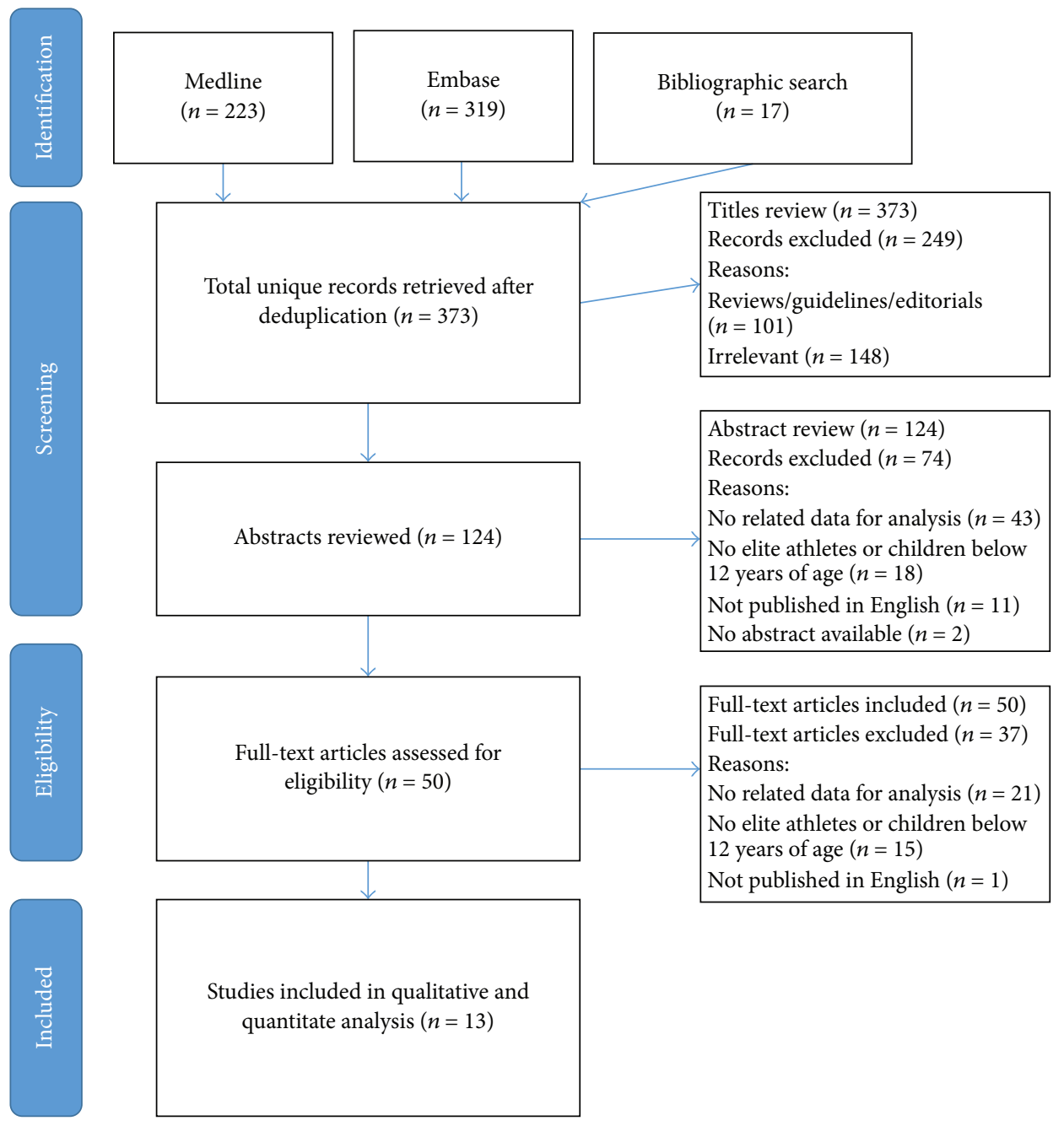

FIGURE 1: Data extraction and analysis.

unfortunate that we had to exclude studies dated from the last decades of the past millennium due to poorly reported diagnostic methods, and therefore a long-term comparison with the normal population cannot be achieved.

The wide range of results might also suggest heterogeneity of either the population or sampling methods. Therefore, we have examined the prevalence in the separate subgroups (land, water, and cold air) according to the environment where they spent the most training hours. After doing so, the range narrows and is easier to interpret. For example, track and field athletes do not suffer from rhinitis significantly more than general population, regardless of being endurance or sprint specialists [18]. On the contrary, $48.6 \%$ of athletes who spend training hours in cold environment report rhinitis and the distinctive symptom is rhinorrhea (96\%), often severe [15]. Aquatic environment causes a similar pattern, with analysis of all studied swimmers reporting rhinitis in 56\% to $74 \%[8,21,28]$. Bougault et al. in the case-control study showed a significant difference of rhinitis prevalence (AR + NAR) between the swimmers and healthy controls (74\% versus $40 \%$, resp., $P<0.01$ ) [8]. The assumption would be that the rhinitis in swimmers is nonallergic in nature due to chlorine irritation and coexists with AR probably in higher prevalence compared to the normal population. Unfortunately, studies which satisfied the inclusion criteria did not examine the prevalence of NAR phenotype separately. Athletes are also known to suffer with exercise-induced rhinitis which is characterized by short-term rhinitic symptoms triggered by the exercise [29]. Interestingly, the prevalence of exercise-induced rhinitis was similar in between swimmers and runners [30]. We have excluded studies examining this entity as our study was focused on chronic rhinitis.

Moreover, many patients with rhinitis without asthma demonstrate nonspecific bronchial hyperresponsiveness after exercise or methacholine, this being a risk factor for developing asthma which is reported between $3.7 \%$ and $22.8 \%$ in athletes. If epidemiological studies indicate that rhinitis and asthma often coexist, prospective studies suggest that rhinitis frequently precedes the development of asthma [28]. When the two risk factors, sporting activity and atopy, were combined in a logistic regression model, the relative risk of asthma was surprisingly high: 25 -fold in an atopic speed 
TABLE 1: Prevalence of Rhinitis in Athletes.

\begin{tabular}{|c|c|c|c|c|c|c|c|}
\hline Study & Design & $\begin{array}{l}\text { Participants } \\
(n)\end{array}$ & $\begin{array}{l}\text { Number of } \\
\text { participants per } \\
\text { environment }\end{array}$ & Diagnosis & $\mathrm{AR}$ & NAR & $\begin{array}{l}\text { Rhinitis (AR + } \\
\text { NAR) }\end{array}$ \\
\hline $\begin{array}{l}\text { Katelaris et al. } \\
(2000)[14]\end{array}$ & Cohort study & 214 & $96 \mathrm{~L}, 118 \mathrm{~W}, 0 \mathrm{CA}$ & Quest. + SPT & $41 \%$ & & \\
\hline $\begin{array}{l}\text { Bonadonna et al. } \\
\text { (2001) [15] }\end{array}$ & Cohort study & 144 & $0 \mathrm{~L}, 0 \mathrm{~W}, 46 \mathrm{CA}$ & $\begin{array}{c}\text { Self-reported } \\
\text { physician } \\
\text { diagnosis }\end{array}$ & & & $46 \%$ \\
\hline $\begin{array}{l}\text { Alaranta et al. } \\
(2005)[16]\end{array}$ & $\begin{array}{l}\text { Case-control } \\
\text { study }\end{array}$ & $\begin{array}{l}446+1504 \\
\text { controls }\end{array}$ & $266 \mathrm{~L}+\mathrm{W}, 180 \mathrm{CA}$ & $\begin{array}{c}\text { Self-reported } \\
\text { physician } \\
\text { diagnosis }\end{array}$ & $36.1 \%$ & & \\
\hline $\begin{array}{l}\text { Silvers and Poole } \\
\text { (2006) [17] }\end{array}$ & Cohort study & 55 & $55 \mathrm{~L}, 0 \mathrm{~W}, 0 \mathrm{CA}$ & $\begin{array}{c}\text { Self-reported } \\
\text { physician } \\
\text { diagnosis }\end{array}$ & $49 \%$ & & \\
\hline $\begin{array}{l}\text { Katelaris et al. } \\
(2006)[18]\end{array}$ & Cohort study & 980 & $980 \mathrm{~W}+\mathrm{L}, 0 \mathrm{CA}$ & Quest. + SPT & $24 \%$ & & \\
\hline $\begin{array}{l}\text { Macucci et al. } \\
(2007)[19]\end{array}$ & Cohort study & 352 & $352 \mathrm{~L}, 0 \mathrm{~W}, 0 \mathrm{CA}$ & Quest. + SPT & $22.16 \%$ & & \\
\hline $\begin{array}{l}\text { Bonini et al. (2007) } \\
{[20]}\end{array}$ & $\begin{array}{c}\text { Case-control } \\
\text { study }\end{array}$ & 98 & $98 \mathrm{~W}+\mathrm{L}, 0 \mathrm{CA}$ & Quest. + SPT & $34.7 \%$ & & \\
\hline $\begin{array}{l}\text { Rong et al. (2008) } \\
\text { [21] }\end{array}$ & $\begin{array}{l}\text { Case-control } \\
\text { study }\end{array}$ & $\begin{array}{l}23+30 \\
\text { controls }\end{array}$ & $0 \mathrm{~L}, 23 \mathrm{~W}, 0 \mathrm{CA}$ & $\begin{array}{c}\text { Self-reported } \\
\text { physician } \\
\text { diagnosis }\end{array}$ & $56.5 \%$ & & \\
\hline $\begin{array}{l}\text { Clearie et al. (2010) } \\
{[22]}\end{array}$ & Cohort study & 61 & $61 \mathrm{~W}$ & $\begin{array}{l}\text { Physician } \\
\text { diagnosis }\end{array}$ & & & $40 \%$ \\
\hline $\begin{array}{l}\text { Thomas et al. } \\
\text { (2010) [23] }\end{array}$ & Cohort study & 291 & $291 \mathrm{~L}+\mathrm{W}, 0 \mathrm{CA}$ & $\begin{array}{c}\text { Self-reported } \\
\text { physician } \\
\text { diagnosis }\end{array}$ & $25.4 \%$ & & \\
\hline $\begin{array}{l}\text { Bougault et al. } \\
(2010)[8]\end{array}$ & $\begin{array}{c}\text { Case-control } \\
\text { study }\end{array}$ & $\begin{array}{l}39+30 \\
\text { controls }\end{array}$ & $0 \mathrm{~L}, 39 \mathrm{~W}, 0 \mathrm{CA}$ & $\begin{array}{c}\text { Physician } \\
\text { diagnosis + SPT }\end{array}$ & & & $74 \%$ \\
\hline $\begin{array}{l}\text { Kurowski et al. } \\
(2016)[7]\end{array}$ & Cohort study & 222 & $214 \mathrm{~L}, 8 \mathrm{~W}, 0 \mathrm{CA}$ & $\begin{array}{c}\text { Physician } \\
\text { diagnosis + SPT }\end{array}$ & $21 \%$ & $6 \%$ & $27 \%$ \\
\hline $\begin{array}{l}\text { Bonini et al. (2015) } \\
{[24]}\end{array}$ & Cohort study & 659 & $606 \mathrm{~L}, 38 \mathrm{~W}, 15 \mathrm{CA}$ & Quest. + SPT & $26.2 \%$ & & \\
\hline
\end{tabular}

L: land, W: water, and CA: cold air.

and power athlete, 42-fold in an atopic long-distance runner, and 97 -fold in atopic swimmers compared with nonatopic controls [31].

\section{Conclusion}

Rhinitis in the athlete is an emerging field of interest. The published evidence identified in this systematic review illustrates the need for precision when analysing this particular population: to take care to define both the individual studied (and their exercise environment) and the condition identified (allergic or nonallergic). Although individual studies suggest an increase in prevalence of rhinitis in the land-based athlete, systematic review of the literature does not reveal any convincing trend of a higher prevalence compared to the general population. By contrast, aquatic and cold air athletes both demonstrate an increased prevalence of rhinitis-reflecting the irritant effects of their environment on the nasal mucosa.

\section{Conflicts of Interest}

The authors declare that they have no conflicts of interest.

\section{References}

[1] E. O. Meltzer, "Quality of life in adults and children with allergic rhinitis," The Journal of Allergy and Clinical Immunology, vol. 108, no. 1, pp. S45-S53, 2001.

[2] W. A. Greisner III, R. J. Settipane, and G. A. Settipane, "Coexistence of asthma and allergic rhinitis: a 23-year follow-up study of college students," Allergy and Asthma Proceedings, vol. 19, no. 4, pp. 185-188, 1998.

[3] N. S. Dallimore and R. Eccles, "Changes in human nasal resistance associated with exercise, hyperventilation and rebreathing," Acta Oto-Laryngologica, vol. 84, no. 1-6, pp. 416-421, 1977.

[4] V. Niinimaa, P. Cole, S. Mintz, and R. J. Shephard, "The switching point from nasal to oronasal breathing," Respiration Physiology, vol. 42, no. 1, pp. 61-71, 1980. 
[5] S. Bonini, M. Bonini, J. Bousquet et al., "Rhinitis and asthma in athletes: an ARIA document in collaboration with GA2LEN," Allergy: European Journal of Allergy and Clinical Immunology, vol. 61, no. 6, pp. 681-692, 2006.

[6] A. Walker, P. Surda, M. Rossiter, and S. Little, "Nasal function and dysfunction in exercise," The Journal of Laryngology and Otology, vol. 130, no. 5, pp. 431-434, 2016.

[7] M. Kurowski, J. Jurczyk, H. Krysztofiak, and M. L. Kowalski, "Exercise-induced respiratory symptoms and allergy in elite athletes: Allergy and Asthma in Polish Olympic Athletes ( $\left.\mathrm{A}^{2} \mathrm{POLO}\right)$ project within GA ${ }^{2} \mathrm{LEN}$ initiative," The Clinical Respiratory Journal, vol. 10, no. 2, pp. 231-238, 2016.

[8] V. Bougault, J. Turmel, and L. P. Boulet, "Effect of intense swimming training on rhinitis in high-level competitive swimmers," Clinical and Experimental Allergy, vol. 40, no. 8, pp. 1238-1246, 2010.

[9] V. Bauchau and S. R. Durham, "Epidemiological characterization of the intermittent and persistent types of allergic rhinitis," Allergy: European Journal of Allergy and Clinical Immunology, vol. 60, no. 3, pp. 350-353, 2005.

[10] M. Jessen and L. Malm, "Definition, prevalence and development of nasal obstruction," Allergy: European Journal of Allergy and Clinical Immunology, vol. 52, supplement 40, pp. 3-6, 1997.

[11] H. S. Varonier, J. De Haller, and C. Schopfer, "Prevalence of allergy in children and adolescents," Helvetica Paediatrica Acta, vol. 39, no. 2, pp. 129-136, 1984.

[12] C. Bachert, P. van Cauwenberge, J. Olbrecht, and J. van Schoor, "Prevalence, classification and perception of allergic and nonallergic rhinitis in Belgium," Allergy: European Journal of Allergy and Clinical Immunology, vol. 61, no. 6, pp. 693-698, 2006.

[13] R. A. Settipane and D. R. Charnock, "Epidemiology of rhinitis: allergic and nonallergic," Clinical Allergy and Immunology, vol. 19, pp. 23-34, 2007.

[14] C. H. Katelaris, F. M. Carrozzi, T. V. Burke, and K. Byth, "A springtime Olympics demands special consideration for allergic athletes," The Journal of Allergy and Clinical Immunology, vol. 106, no. 2, pp. 260-266, 2000.

[15] P. Bonadonna, G. Senna, P. Zanon et al., "Cold-induced rhinitis in skiers-clinical aspects and treatment with ipratropium bromide nasal spary: a randomized controlled trial," American Journal of Rhinology, vol. 15, no. 5, pp. 297-301, 2001.

[16] A. Alaranta, H. Alaranta, M. Heliövaaras, P. Alha, P. Palmu, and I. Helenius, "Allergic rhinitis and pharmacological management in elite athletes," Medicine and Science in Sports and Exercise, vol. 37, no. 5, pp. 707-711, 2005.

[17] W. S. Silvers and J. A. Poole, "Exercise-induced rhinitis: a common disorder that adversely affects allergic and nonallergic athletes," Annals of Allergy, Asthma \& Immunology, vol. 96, no. 2, pp. 334-340, 2006.

[18] C. H. Katelaris, F. M. Carrozzi, T. V. Burke, and K. Byth, "Patterns of allergic reactivity and disease in Olympic athletes," Clinical Journal of Sport Medicine, vol. 16, no. 5, pp. 401-405, 2006.

[19] F. Macucci, L. Guerrini, and M. Strambi, "Asthma and allergy in young athletes in Siena Province. Preliminary results," The Journal of Sports Medicine and Physical Fitness, vol. 47, no. 3, pp. 351-355, 2007.

[20] M. Bonini, G. Lapucci, G. Petrelli et al., "Predictive value of allergy and pulmonary function tests for the diagnosis of asthma in elite athletes," Allergy: European Journal of Allergy and Clinical Immunology, vol. 62, no. 10, pp. 1166-1170, 2007.
[21] C. Rong, H. Bei, M. Yun, W. Yuzhu, and Z. Mingwu, "Lung function and cytokine levels in professional athletes," The Journal of Asthma, vol. 45, no. 4, pp. 343-348, 2008.

[22] K. L. Clearie, P. A. Williamson, S. Vaidyanathan et al., "Disconnect between standardized field-based testing and mannitol challenge in Scottish elite swimmers," Clinical and Experimental Allergy, vol. 40, no. 5, pp. 731-737, 2010.

[23] S. Thomas, B. Wolfarth, C. Wittmer, D. Nowak, and K. Radon, "Self-reported asthma and allergies in top athletes compared to the general population-results of the German part of the GA2LEN-Olympic study 2008," Allergy, Asthma and Clinical Immunology, vol. 6, no. 1, article 31, 2010.

[24] M. Bonini, C. Gramiccioni, D. Fioretti et al., "Asthma, allergy and the olympics: A 12-year survey in elite athletes," Current Opinion in Allergy and Clinical Immunology, vol. 15, no. 2, pp. 184-192, 2015.

[25] J. Bousquet, N. Khaltaev, A. A. Cruz et al., "Allergic Rhinitis and its Impact on Asthma (ARIA) 2008," Allergy: European Journal of Allergy and Clinical Immunology, vol. 63, no. 86, pp. 8-160, 2008.

[26] P. Lieberman and D. Pattanaik, "Nonallergic rhinitis," Current Allergy and Asthma Reports, vol. 14, article 439, 2014.

[27] R. N. Enberg, "Perennial nonallergic rhinitis: a retrospective review," Annals of Allergy, vol. 63, no. 6, pp. 513-516, 1989.

[28] R. Shaaban, M. Zureik, D. Soussan et al., "Rhinitis and onset of asthma: a longitudinal population-based study," The Lancet, vol. 372, no. 9643, pp. 1049-1057, 2008.

[29] A. Walker, P. Surda, M. Rossiter, and S. Little, "Rhinitis in elite and non-elite field hockey players," International Journal of Sports Medicine, vol. 38, no. 1, pp. 65-70, 2017.

[30] A. Alves, C. Martins, L. Delgado, J. Fonseca, and A. Moreira, "Exercise-induced rhinitis in competitive swimmers," American Journal of Rhinology \& Allergy, vol. 24, no. 5, pp. el14-e117, 2010.

[31] I. J. Helenius, H. O. Tikkanen, S. Sarna, and T. Haahtela, "Asthma and increased bronchial responsiveness in elite athletes: atopy and sport event as risk factors," The Journal of Allergy and Clinical Immunology, vol. 101, no. 5, pp. 646-652, 1998. 


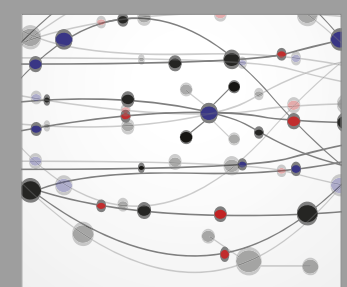

The Scientific World Journal
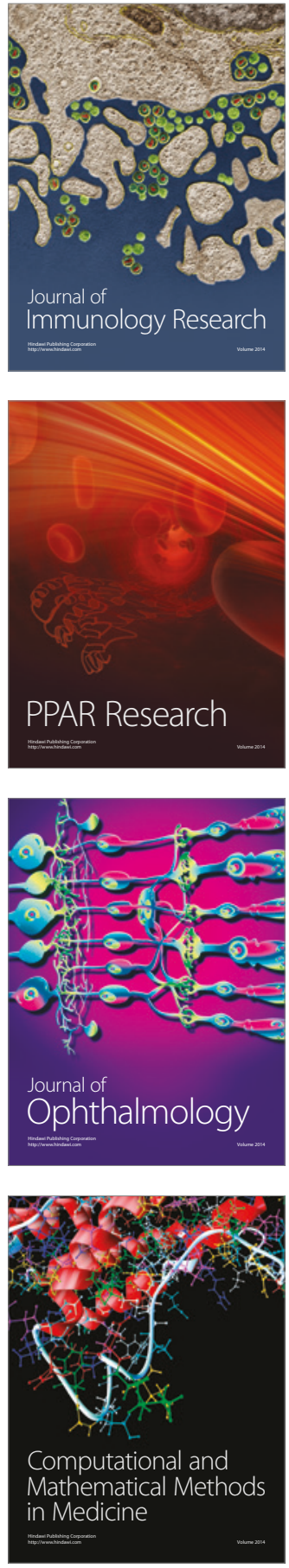

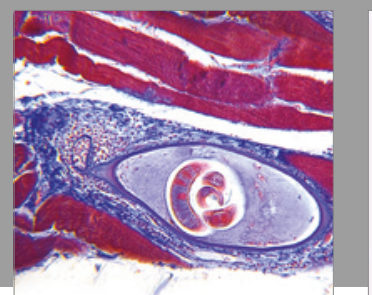

Gastroenterology Research and Practice
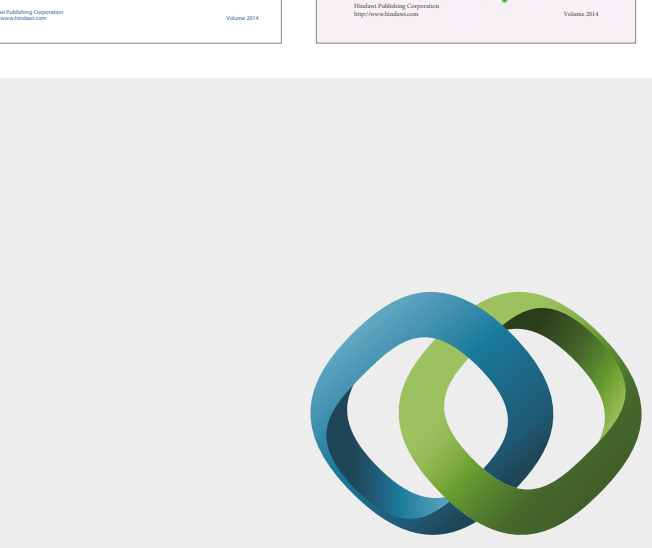

\section{Hindawi}

Submit your manuscripts at

https://www.hindawi.com
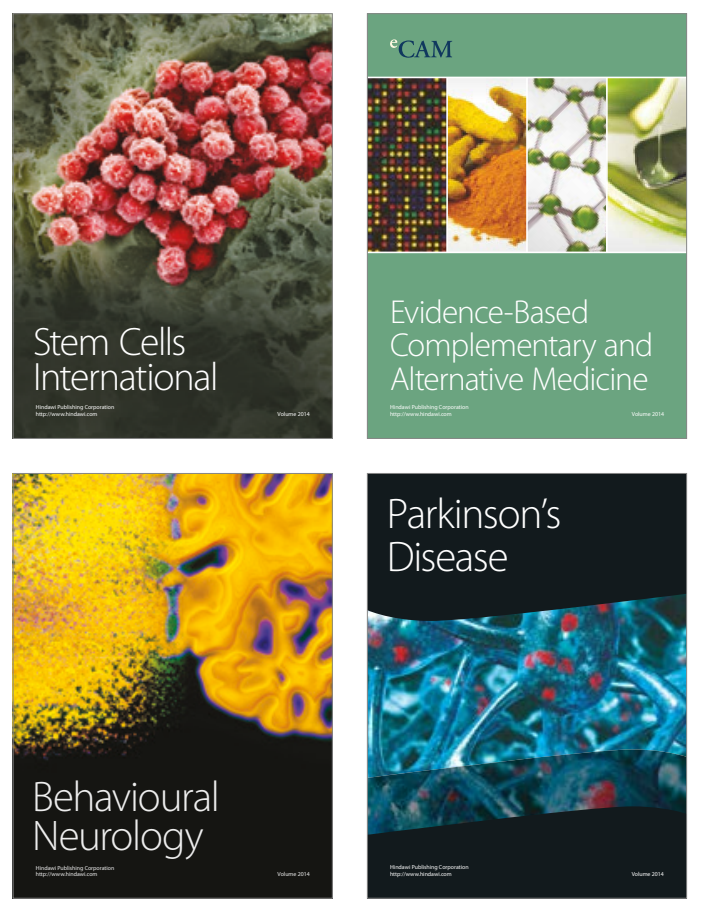
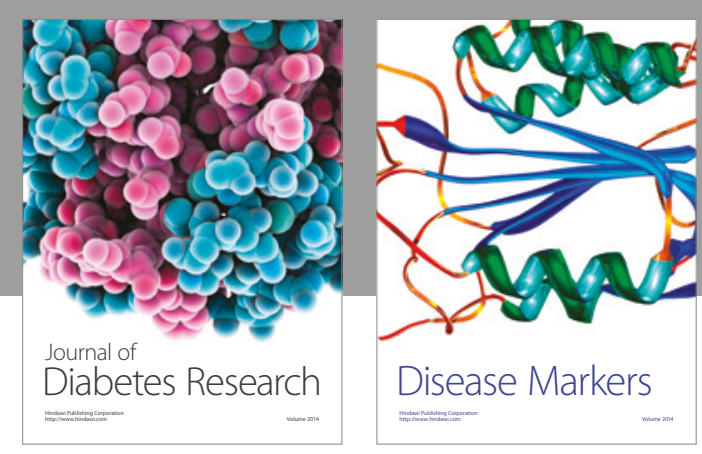

Disease Markers
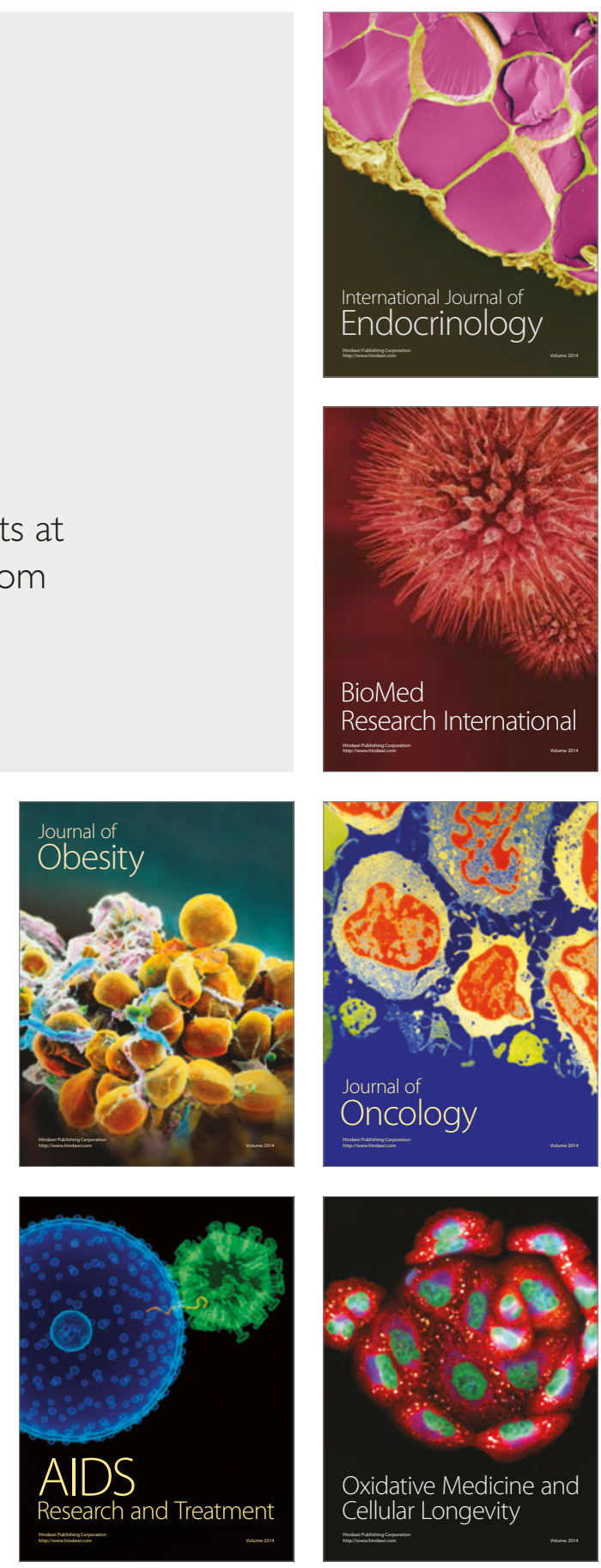